\title{
Editorial
}

\section{0 imperativo da transparência no tratamento das doenças da coluna}

\section{The need for transparency in the treatment of spinal diseases}

\author{
Paulo Marcelo Zimmer ${ }^{1}$
}

$\mathrm{O}$ artigo intitulado "A redução do custo em cirurgia de coluna em um centro especializado de tratamento"(1), publicado nesta edição da einstein, mostra a economia de um centro de tratamento especializado, realizando um serviço de segunda opinião. Além dos achados de caráter econômico, chama atenção a divergência de opiniões quanto à conduta terapêutica, evidenciadas por meio de um algoritmo de segunda opinião, iniciado após uma indicação inicial de cirurgia de coluna. O possível viés conservador deste algoritmo foi minimizado pela liberdade conferida aos pacientes de recusarem a participar, e de poder realizar a cirurgia com o médico de origem nos casos em que se confirmava a indicação cirúrgica. Aproximadamente $75 \%$ dos casos que tinham uma indicação cirúrgica poderiam ter sido tratados sem cirurgia.

A falta de diretrizes de tratamento, baseadas em evidências, para as doenças que afetam a coluna vertebral é uma realidade. A revisão sistemática de Cheng et al. clama pela necessidade do desenvolvimento de diretrizes para tratamento de doenças da coluna vertebral com adequada qualidade metodológica, transparência, e consistência com as diretrizes do Appraisal of Guidelines Research and
Evaluation $^{(2)}$. A ausência de diretrizes para guiar o diagnóstico e tratamento das afecções da coluna vertebral contribui para a grande variabilidade nas condutas terapêuticas.

Outro fator que dificulta a formação de diretrizes é a velocidade com que a indústria de implantes e dispositivos cirúrgicos lança novas tecnologias, muito maior do que a da produção de pesquisas que possam comprovar sua eficácia. O uso de Bone Morphogenetic Proteins (BMPs) em cirurgias de artrodese da coluna é um bom exemplo disso. O artigo de Cahill et al. usando o Nationwide Inpatient Sample Database mostra que o uso de BMPs em artrodeses tem uma taxa maior de complicações e um custo mais elevado quando comparado com as artrodeses sem uso de $\mathrm{BMPs}^{(3)}$. Atualmente, o uso de BMPs está praticamente proscrito das artrodeses cervicais e com poucas e discutíveis indicações para a coluna lombar. Mesmo quando os resultados dos novos dispositivos são mostrados em publicações científicas, devemos ter cuidado. Okike et al. mostraram que a publicação de resultados positivos é mais provável quando os autores possuem conflito de interesse com a indústria de implantes ${ }^{(4)}$. 
O possível conflito de interesse de cirurgiões com a indústria também é um fator a ser considerado. $\mathrm{O}$ artigo de Healy \& Peterson descreve a investigação do Departamento de Justiça dos Estados Unidos sobre a relação entre a indústria ortopédica e médicos ortopedistas $^{(5)}$. A alegação é de que a indústria oferece incentivos financeiros ilegais aos ortopedistas. Isto contraria o Federal Health Care Fraud and Abuse Anti-Kickback Statute para programas como o Medicare e Medicaid, podendo interferir no julgamento médico e levar a potencial dano ao paciente. ${ }^{(5)}$

Independentemente das causas que possam ter gerado as divergências quanto às condutas terapêuticas descritas no artigo da einstein, são necessárias ações para reduzi-las em prol do paciente. O desenvolvimento de pesquisas científicas com alto rigor metodológico para a criação de diretrizes, bem como a criação de políticas para impedir o conflito de interesses entre médicos e a indústria farmacêutica são iniciativas importantes para atingir este objetivo.
Neste cenário, é importante reforçar a ideia de que a qualidade dos materiais e instrumentais médicos e o custo do tratamento são fatores importantes, mas o foco central desta discussão sempre deve ser a saúde e a segurança do paciente.

\section{REFERÊNCIAS}

1. Viola DC, Lenza M, Almeida SL, OF, Cendoroglo Neto M, Lottenberg CL et al Spine surgery cost reduction at a specialized treatment center. einstein (São Paulo). 2013;11(1):102-7.

2. Cheng JS, Lee MJ, Massicotte E, Ashman B, Gruenberg M, Pilcher LE, Skelly AC. Clinical guidelines and payer policies on fusion for the treatment of chronic low back pain. Spine (Phila Pa 1976). 2011;36(21 Suppl):S144-63.

3. Cahill KS, Chi JH, Day A, Claus EB. Prevalence, complications, and hospital charges associated with use of bone-morphogenetic proteins in spinal fusion procedures. JAMA. 2009;302(1):58-66.

4. Okike K, Kocher MS, Mehlman CT, Bhandari M. Conflict of interest in orthopaedic research. An association between findings and funding in scientific presentations. J Bone Joint Surg Am. 2007;89(3):608-13.

5. Healy WL, Peterson RN. Department of Justice investigation of orthopaedic industry. J Bone Joint Surg Am. 2009 ;91(7):1791-805. 